\title{
MODELOS DE SAÚDE NACIONAL: CONSEQUÊNCIAS EM MEIO À CRISE
}

\author{
Igor Souza Leonel
}

\begin{abstract}
RESUMO
O artigo pretende analisar as formas de atendimento de saúde ofertadas no Brasil, diante de suas premissas, conjunturas e falhas. Mostra como a saúde pública possui uma boa imagem na sociedade, ainda que não consiga executar aquilo que foi prescrito em lei- devido a suas limitações. A saúde privada, do alto do pedestal de exclusividade, se torna frágil diante de situações adversas, com implicações que ela não pode controlar. A pesquisa buscou argumentos em dados estatísticos (que apontam avanços no setor no decorrer dos anos) e na análise critica dos dois setores (público e privado), assim como em suas regras primarias e deveres regidos pela constituição federal.
\end{abstract}

Palavras-chave: saúde, saúde pública, saúde privada, crise.

\section{ABSTRACT}

The article intends to analyze the forms of health care offered in Brazil in face of its premises, conjunctures and failures. It shows how public health has a good image in society, even though it cannot carry out what has been prescribed in law because of its limitations. Private health, from the top of the pedestal of exclusivity, becomes fragile in the face of adverse situations, with implications that it cannot control. The research looked for arguments in statistical data (that indicate advances in the sector over the years) and critical analysis of the two sectors (public and private), as well as in its primary rules and duties governed by the federal constitution.

Keywords: health, public health, private health, crisis. 


\section{Introdução}

A Constituição Federal de 1988, em seu Art. 196, declara que a:

"saúde é um direito de todos e dever do Estado, garantida mediante políticas sociais e econômicas que visam à redução do risco de doença e de outros agravos e possibilitando o acesso universal e igualitário às ações e serviços para a promoção, proteção e recuperação" (BRASIL, 1996).

Tal declaração de direito coloca grande responsabilidade nas mãos do governo. Com isso abre-se margem para que o sistema de saúde, a fim de fornecer de fato o que foi prescrito, se divida em subníveis: um subsistema público de saúde, representado pelo SUS (Sistema Único de Saúde); e um subsistema privado, representado pelas operadoras de seguros saúde (Saúde Suplementar) e os liberais clássicos, profissionais autônomos.

Paim (2015), em seu livro "O que é SUS", explica que as diretrizes do SUS, promulgadas no Pacto pela Saúde de 2006, definem seus princípios e diretrizes como a universalidade do acesso, integralidade da atenção e descentralização político-administrativa com direção única em cada esfera de governo. O Sistema Único de Saúde tem suas bases estruturais fincadas em objetivos como o atendimento a qualquer pessoa localizada no território nacional, com equidade e devida atenção.

"Entretanto, o setor Público vem continuamente expondo suas iniquidades, que, submetidas a constantes críticas e inequívocos exemplos de ineficiência, serviram como grande atrativo para os planos de saúde privados ampliarem sua atuação no mercado" (SILVA apud PIETROBON; PRADO; CAETANO, 2008, p. 769).

$\mathrm{O}$ desafio de efetivar o atendimento universal e igualitário em uma nação que tem dimensões continentais faz com que o resultado obtido, de um projeto tão bem intencionado, seja a ineficiência e a depreciação por aqueles que o utilizam. As consequências apontadas por Silva (2003) podem ser vinculadas à forma com que o Sistema Único de Saúde é gerido, a saber, descentralizado e regionalizado (municipalização), o que o impediria de ter uma regulamentação assertiva e ofertar o mesmo padrão de atendimento em todas as regiões.

A saúde privada, no entanto, aparenta existir justamente para completar uma lacuna que a saúde pública não consegue (ou talvez não possa) dispor para seus usuários. A demanda por atendimento do SUS pode, neste contexto, ser considerada uma fração da demanda total, devido à existência da saúde privada - que capta parte dos usuários públicos, tornando-os beneficiários de seguros saúde. Segundo dados disponibilizados no relatório da ANS (Agencia Nacional de Saúde Suplementar) de 2016, 66\% dos mais de 47 milhões de beneficiários em planos de saúde estão em planos privados por medidas de contratação empresarial (ANS, 2016); ou seja, quando um novo funcionário ingressa na companhia, ele 
tem a sua disposição o acesso ao plano de saúde "automaticamente". Outros 20\%, aproximadamente, recorrem à contração de planos de saúde individuais (ANS, 2016), que comumente tem valores mais caros, quando comparados aos empresariais. Há diversos fatores que fazem um cidadão aceitar se comprometer com uma quantia de dinheiro para obter algo que está sendo ofertado, pelo Governo, gratuitamente. Gastar com saúde é buscar por um atendimento superior ao ofertado nas redes básicas do SUS. Contratar um plano de saúde é se considerar melhor assistido quando se está doente, além de poder gozar de um status de "pseudo exclusividade" - por ter algo diferenciado em relação aos demais. Porém, o seguro saúde (ou o plano de saúde) é investimento em um serviço que não se pretende utilizar. É o tipo de produto intangível que, além de oferecer segurança na maior parte do tempo de contratação, deve estar à plena disposição quando for solicitado. $\mathrm{O}$ que nem sempre é a realidade dos planos mais básicos.

A ANS, a fim de promover maior cobertura, atualiza periodicamente (a cada dois anos) os serviços da tabela de tratamentos e coberturas (inclusive acrescentando novos serviços), que devem ser ofertados pelas operadoras de planos de saúde. As operadoras, não interessadas em ofertar mais, encontram, por sua vez, alternativas para limitar a quantidade de tratamento que um usuário pode ter acesso, através, por exemplo, de subterfúgios burocráticos. Os planos de baixo custo, com maior acesso de pessoas com renda inferior, são vendidos de forma exacerbada, inflando os prestadores de serviços médicos e "sucateando" o atendimento. Isso acarreta uma demanda de reclamações que a agência recepciona, sendo que mais de $67 \%$ delas são de temas referentes a coberturas e atendimentos, segundo a ANS (2016).

\section{Setor da Saúde em tempos de Crise}

A crise "iniciada" em 2014 deixa marcas na vida da sociedade. A renda reduziu e com ela consumo e gastos que antes eram comuns passaram a ter acessos menos abrangentes. Um exemplo deles é a saúde para aqueles que ficaram desempregados. O Instituto Observatório Social divulgou em 2016, os dados do IBGE, informando que o número de desempregados no Brasil chegou a 7,7 milhões no ano de 2015. O IBGE (2017) informou que a população desempregada chegou a 14,2 milhões, no primeiro trimestre. Conforme citado anteriormente, $66 \%$ dos planos de saúdes vendidos são por medidas de contratação empresariais. Uma vez

que a redução de empregos não afeta diretamente só os desempregados, e sim a toda a 
economia que deixa de receber maior oferta de dinheiro, sendo assim o mercado de saúde privado reage diante desta contingência.

Nos anos de 2014 a 2016 é notado um declínio nas contratações de novos planos de saúde conforme o gráfico abaixo:

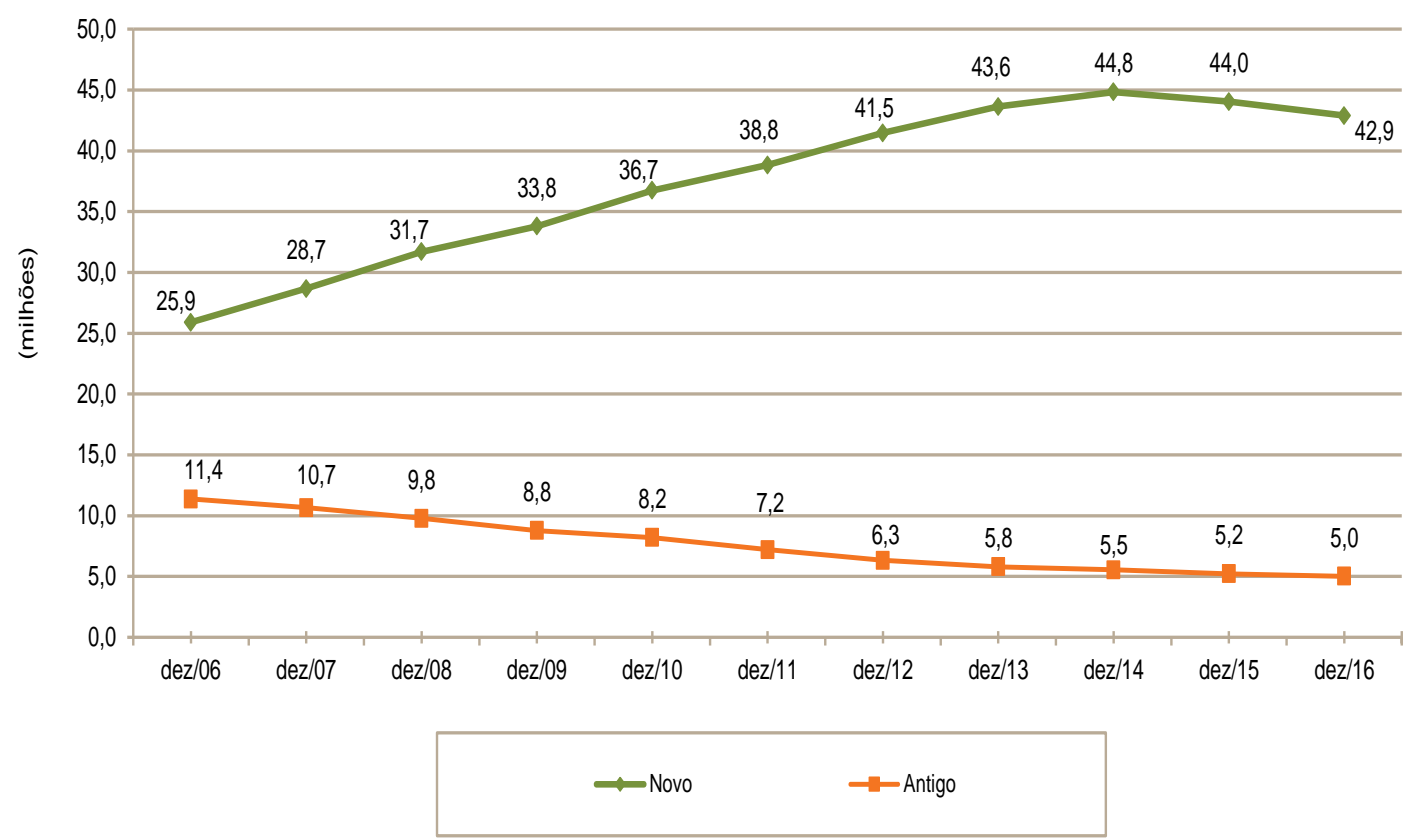

Beneficiários de planos de assistência médica por época de contratação do plano

(Brasil - dezembro/2016)

Fonte: SIB/ANS/MS - 12/2016

É possível observar que após crescente numero de contratações por ano, os anos subsequentes a 2014 apresentaram variações negativas, sendo que o ano de 2016 regride a valores similares aos observados entre 2012 e 2013. Em comparação semelhante, no gráfico abaixo é possível ver a variação no número de beneficiários em regimes de contratação. $\mathrm{O}$ número mais expressivo é o referente ao coletivo empresarial, devido sua maior oferta entre as operadoras de saúde e sua fácil acessibilidade por ser totalmente ou parcialmente custeada pelo empregador. 


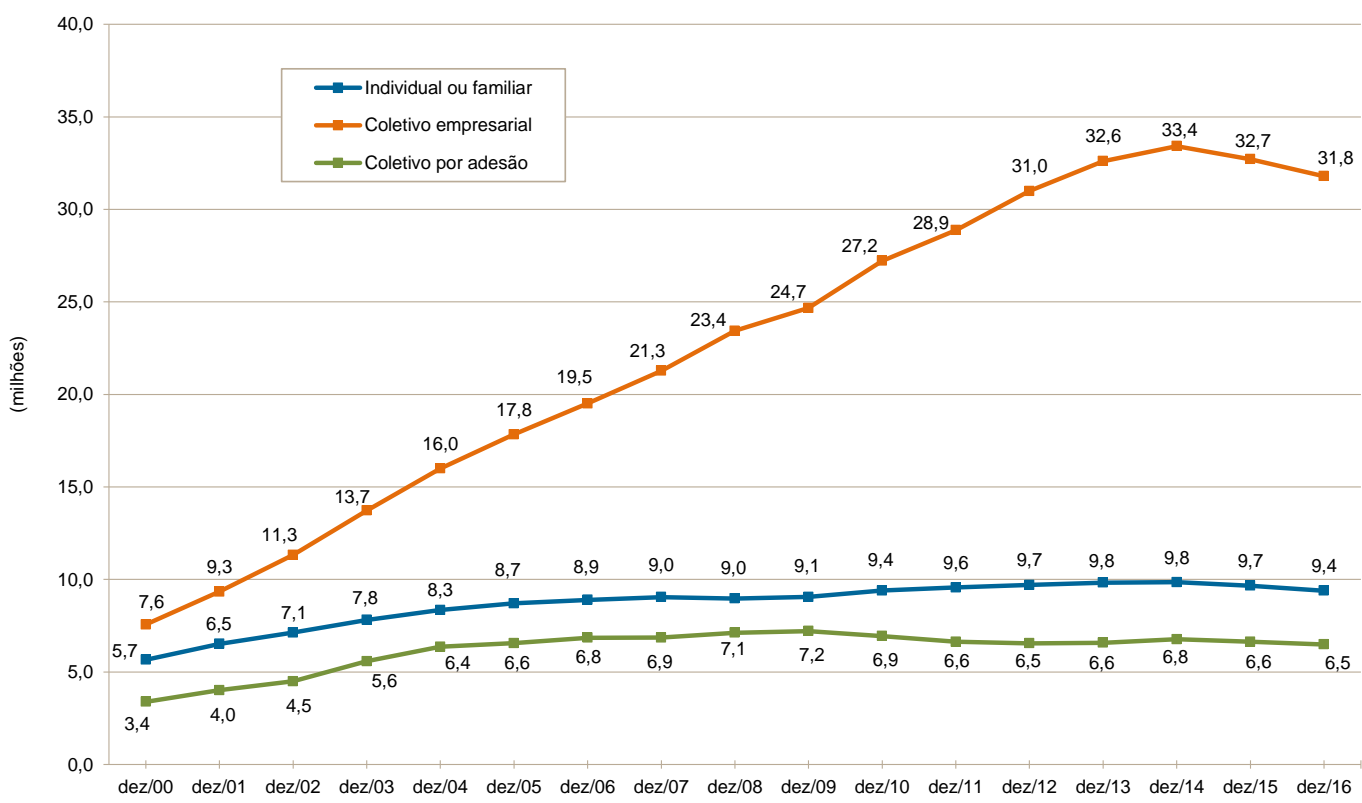

Beneficiários de planos de assistência médica por tipo de contratação do plano

(Brasil-2000-2016)

Fonte: SIB/ANS/MS - 12/2016

Com os desafios da crise e o desemprego crescente, se torna impossível que esta curva continue positivamente inclinada, já que as demissões em massa e o fechamento de postos de trabalho acarretam consequentemente no declínio nos números de desempenho da saúde privada.

\section{Conclusão}

No presente artigo foi possível observar que a saúde publica no Brasil tem uma ação diferenciada quando comparada à saúde privada. Além do caráter similar de recuperação da saúde, o SUS também tem o dever de promover e prevenir. Analisando a critica realiza para o não atendimento efetivo da premissa da universalidade do SUS, podemos concluir que o sua falha não está ligada ao projeto, que foi muito bem escrito, e sim a quem realiza sua gestão, ou seja, seu problema é político acima de tudo. A saúde privada, como agente suplementar, oferta parte do atendimento a saúde que deveria ser realizada pelo Estado. As operadoras de saúde, como empresas liberais, buscam o lucro e apesar de terem a intenção de ofertar um bom serviço aos seus consumidores, jamais deixaram suas despesas superarem seu faturamento, por isso, a burocracia para conseguir um tratamento se torna uma aliada às operadoras e uma inimiga para os usuários. O estudo de caso, referente a crise, evidencia a fragilidade da saúde privada que tem seu maior produto sendo os planos coletivos empresarias, mas que em época de crise passam a não vender tanto quanto antes e ainda 
perdem beneficiários. Mesmo com a crise ainda são mais de 47 milhões de beneficiários, porém outros 2,5 milhões deixaram de ser atendidos pela rede privada e se tornaram potenciais usuários do SUS. Com isso evidencio o papel central que o SUS fornece a sociedade brasileira, a segurança no fornecimento de saúde acima de qualquer crise. 


\section{Referências Bibliográficas}

ANS. Sistema de Informações de Beneficiários/ANS/MS - 12/2016. Disponível em: http://www.ans.gov.br/perfil-do-setor/dados-gerais. Acesso em: 27 de abril de 2017 BRASIL. Constituição (1988). Constituição da República Federativa do Brasil. Brasília, DF. Art. 196: Senado Federal. Disponível em: <https://www.senado.gov.br/atividade/const/con1988/CON1988_05.10.1988/art_196_.asp>. Acesso em: 29 de Abril de 2017.

BRASIL. Pacto pela Saúde - Consolidação do SUS e aprova as Diretrizes Operacionais do Referido Pacto. Portaria $\mathrm{N}^{\mathrm{o}}$ 399, DATA. Disponível em: http://bvsms.saude.gov.br/bvs/saudelegis/gm/2006/prt0399_22_02_2006.html>. Acesso em 20 de Março de 2017.

IBGE. PNAD Contínua: taxa de desocupação vai a $13,7 \%$ no trimestre encerrado em março de 2017. $\quad$ Disponível em: http://saladeimprensa.ibge.gov.br/noticias?view=noticia\&id=1\&busca=1\&idnoticia=3420. Acesso em: 01 de Maio de 2017.

INSTITUTO OBSERVATORIO SOCIAL (Brasil). Situação do emprego no Brasil terá melhoras somente em 2017. 2017. Disponível em: $<$ http://www.observatoriosocial.org.br/?q=noticia/situacao-do-emprego-no-brasil-teramelhoras-somente-em-2017>. Acesso em: 29 de Abril de 2017.

PAIM, Jairnilson Silva. O QUE É O SUS. [s. 1.]: Fiocruz, 2015. 92 p. E-book. Disponível em: <http://www.livrosinterativoseditora.fiocruz.br/sus/92/>. Acesso em: 20 mar. 2017.

PIETROBON, Louise; PRADO, Martha Lenise do; CAETANO, João Carlos. Saúde suplementar no Brasil: o papel da Agencia Nacional de Saúde Suplementar na regulação do setor. Revista de Saúde Coletiva, Rio de Janeiro, v. 4, n. 18, p.767-783, 2008.

SOUZA, Georgia Costa de Araujo; COSTA, Iris do Céu Clara. O SUS nos seus 20 anos: reflexões num contexto de mudanças. Saúde Soc., São Paulo, v. 3, n. 19, p.509-517, 01 jan. 2010 .

SILVA, A. A. Relação entre operadoras de planos de saúde e prestadores de serviços: um novo relacionamento estratégico. Porto Alegre. 2003. Disponível em: < http://www.ans.gov.br/portal/site/Biblioteca/biblioteca_topico_17704.asp >. Acesso em: 21 de abril de 2017. 